\title{
Can labour market digitalization increase social mobility? Evidence from a European survey of online platform workers
}

\author{
Nicholas Martindale \& Vili Lehdonvirta \\ University of Oxford \\ Working paper, 8 May 2021
}

\begin{abstract}
Children tend to inherit their parents' social class through the types of jobs they get. However, digital technologies are now transforming the way labour markets work. Candidates are increasingly screened using algorithmic decision making. Skills are validated with online tests and customer feedback ratings. Workplace communications take place over digital media. Could these transformations be undermining the advantages that have accrued to workers with posh accents, family connections, and expensively acquired educational qualifications? We examine this question with survey data from the online (remote) platform economy, a labour market segment in which these digital transformations have progressed furthest $(\mathrm{N}=983)$. The results reveal that online platform workers come largely from privileged class backgrounds. Class also influences (via education) what types of online occupations workers do, from professional services to data entry. However, class background has surprisingly little influence on job quality, which is instead shaped by individual digital metrics such as feedback ratings. These findings cannot be fully reconciled with theories of a shift towards meritocracy nor with theories of a persisting influence of class origins. Instead, labour market digitalization may be decoupling inherited occupation from job quality.
\end{abstract}

Key Words: Class Reproduction, Digital Divide, Occupational Attainment, Online, Platforms, Labour Markets 


\section{Introduction}

Children tend to inherit their parents' social class. A substantial body of research shows how financial capital, social ties, and cultural resources acquired from parents influence the kinds of occupations children end up in, how much they get paid, and the quality of their work (Goldthorpe 2007; Goldthorpe and MacKnight 2006). However, labour markets are currently undergoing significant transformations associated with the adoption of new digital technologies. Candidates are increasingly screened using data and algorithmic decision making. Skills are validated with online tests and customer feedback ratings. Workplace communications take place over digital media. The purpose of this article is to examine how these digital transformations may be affecting the link between parental class and children's occupational attainment.

Research on digital divides has shown that the availability, adoption, and use of new information and communication technologies are marked by disparities that follow established social class divisions (Scheerder, van Deursen and van Dijk 2017). People from more privileged backgrounds tend to be able to obtain greater benefits from new digital technologies (van Deursen and Helsper 2015). This suggests that digital transformations in labour markets could be sustaining or even deepening class divides. However, digital transformations could also be hindering some of the mechanisms through which class reproduction conventionally takes place in labour markets. Expensive degrees, social networks, and posh accents may be less relevant in a quantified, algorithmic, and digitally mediated labour market. This possibility has so far received little attention in the literature. In this article, we study the impacts of these digital transformations on class reproduction by analysing an extreme case: the online market for remote freelance labour, in which digital transformations that are only nascent in the broader labour market have already been widely adopted. The market is underpinned by webbased platforms that validate workers' skills using tests and feedback ratings, match workers with employers in part by using algorithmic recommendations, and digitally mediate communications between the parties. If digital transformations are disrupting the link between parental class and children's occupational outcomes, then we should be able to observe it in this online labour market.

Labour platforms are an increasingly popular research context, but researchers are yet to empirical evaluate class reproduction in this setting. In this article we answer, for the first time, the following questions: (1) What are the parental class backgrounds of people doing online platform work? (2) Among people doing online platform work, do those with more privileged parental class backgrounds obtain better quality work? Our analyses are based on data from a recent survey of 983 freelancers obtaining work via three prominent online labour platforms, who are resident in six European countries: Finland, Germany, Italy, Romania, Spain, and the United Kingdom. Results reveal that people doing online platform work are disproportionately from privileged parental class backgrounds, although there are also many from less privileged backgrounds. Despite this skew towards more privileged workers, among platform workers, we find that, in general, parental class background is not significantly associated with the types of work performed by the workers - their 'online occupations'.

There are two exceptions. First, those doing work categorised as 'Professional Services' are disproportionately from more privileged backgrounds. This disparity is entirely accounted for by differences in educational attainment, suggesting that even in a digitally transformed 
labour market, parental class background can to some extent influence the occupational outcomes of children indirectly through the formal educational system. Second, those doing 'Sales and Marketing' work are likewise disproportionately from more privileged backgrounds, an association that cannot be accounted for using available controls. This suggests that parental class background retains a direct influence on this occupational outcome even in the digitally transformed labour market, likely through the kinds of cultural resources valued in sales work. However, class background has surprisingly little influence on job quality, which is instead shaped by individual digital metrics such as feedback ratings.

Our study presents an empirical contribution to the rapidly growing literature on online platform work and 'gig work', as the first quantitative analysis of class reproduction in this context. Moreover, the study presents a theoretical contribution in extending social mobility debates into digitally transformed work and developing an initial understanding of the mechanisms that can generate social mobility and reproduction in a quantified, algorithmic, digitally mediated labour market. As such, we also contribute to the broader discussion on the impact of digital technologies on social mobility.

\section{Literature Review}

\section{Influence of parental social class on occupational outcomes}

Researchers of inter-generational social mobility have long investigated how parental class influences occupational outcomes for the next generation. Within this research, two broad approaches may be distinguished. The first emphasises the persisting influence of parental social class on occupational outcomes for the next generation and the second emphasises the attenuation of this influence.

Theories of persistence seek to explain why the children of parents with occupations in more privileged class strata tend themselves to attain more privileged occupations in which they earn more and experience greater security than those with less privileged class origins (Friedman and Laurison 2019; Goldthorpe and McKnight 2006). Goldthorpe and his collaborators have influentially explained these outcomes as the direct and indirect result of the resources available to families of different class backgrounds (Goldthorpe 2007; Goldthorpe and McKnight 2006). Differences in class resources indirectly lead to class reproduction through their impact on educational attainment. Parents with more financial resources are often able to secure a higher quality of education for their children. These parents are more likely to pay for private tuition or to move to areas nearer desirable state schools. Their children are also able to acquire a greater quantity of education because parents in more privileged occupations are more able to support them financially for longer periods, through undergraduate and postgraduate study for example. Parents with fewer economic resources may discourage their children from taking riskier and costlier educational paths, as in tertiary education. Instead, such parents may recommend routes which lead more directly into stable employment, such as vocational training, but which tend to have poorer pay and conditions than occupations requiring the possession of an undergraduate degree. As employers use educational attainment as an indicator of skill when hiring workers, and access to many occupations relies on the possession of specific qualifications, differences in educational attainment translate into 
differences in occupational outcomes. Through this indirect educational path, class origins therefore contribute towards class reproduction in the next generation.

Theoretical approaches stressing the persisting influence of class origins on occupational attainment, also argue that class origins have a direct impact on occupational attainment, through social ties and cultural resources (Friedman and Laurison 2019). Parents are more likely to become aware of employment opportunities for their children within their own occupational and social networks (Granovetter 1995). Such networks typically exhibit a significant degree of homophily, including a class dimension, and so contribute towards class reproduction. Class origin influences the kinds of cultural resources that families provide for their children. Not all modes of self-presentation or cultural referents are treated equally by employers, and prejudice towards working class cultural markers is not uncommon in middle class professions (Friedman and Laurison 2019). Cultural resources may therefore hinder upward class mobility for those from lower class origins while conferring suitability on those with middle class origins for more privileged occupations, thereby contributing towards class reproduction.

Against theories of the persistence of class reproduction, a second tradition of social mobility research argues that economic and technological developments are leading to the attenuation of the influence of class origins on occupational attainment. Such approaches have a long history in liberal theories of industrialism (Blau and Duncan 1969; Treiman 1970), postindustrialism (Bell 1973), and the 'knowledge economy' (Unger 2019). Theories of attenuation argue that technological and economic development are leading to the reduced influence of both direct and indirect influences of class origin on occupational attainment. According to this approach, the link between class origin and educational attainment is weakening due to the expansion of educational provision since the mid-twentieth century. Educational expansion is necessary to generate a workforce with sufficient skills to meet the needs of economic and technological development. Primary and secondary education are now free and compulsory in all affluent countries and school leaving ages have gradually risen. In some countries, tertiary education is free or heavily subsidized by the state. To the extent that employers select workers based on educational qualifications, according to attenuation approaches, the indirect link between class origins and occupational attainment should therefore also have weakened. Moreover, as employers in market economies must ensure the productive efficiency and competitiveness of their firms, they select workers whose skills match the needs of their companies. As educational qualifications are the most salient signal of workers' skills, employers increasingly rely on these credentials when selecting workers. Therefore, the influence of other recruitment practices which provide a direct link between class origin and occupational attainment, such as the use of social contacts or cultural discrimination, diminishes over time. As a result of the attenuation of both direct and indirect influence of class origin on occupational attainment, the extent of class reproduction diminishes.

\section{Digital labour market transformations}

While researchers of social mobility have debated which theories of class reproduction prove more accurate, labour markets themselves have continued to change. In particular, much scholarly attention has been paid to the impacts of technological transformations on labour markets. Many influential studies have examined changes in the demand for different types of 
skills as a result of the adoption of computers and automation technologies (e.g. Di Pietro 2002; Frey and Osborne 2017; Rumberger and Levin 1985). In previous eras, job losses linked to automation were concentrated in low-income, routine-intensive occupations (Braverman 1974; Goldin and Katz 1998; Bresnahan 1999). But over the past two decades, technology-induced job losses in Europe and the United States are thought to have taken place predominantly in middle-income manufacturing and clerical jobs (Goos et al. 2009; Autor and Dorn 2013). This is feared to have led to a 'hollowing out' of the labour market, in which jobs that sustain the middle class are eliminated (Goos and Manning 2007; Autor and Dorn 2013).

Yet besides changes in skill content of jobs, the adoption of new technologies is also associated with transformations in employment practices - changes in the 'how' as well as in the 'what'. It is possible to identify at least three such transformations. One is the adoption of telework (Huws et al. 1990) or telecommuting (Mokhtarian 1991), which refers to workers working remotely from their homes, co-working spaces, or similar. As home internet access has improved and office information systems have moved to the cloud, working remotely has slowly become more common (Dunn 2017). The need for social distancing during the 202021 COVID-19 pandemic has greatly accelerated the use of remote working. Digitally mediated remote interaction has also become extremely common in hiring, with the initial interview in many cases being performed via videoconferencing, or even via text-based instant messaging (Sanchez-Monedero and Dencik 2019).

A second, more recent digital transformation is the adoption of AI technologies into human resource management, and especially into the hiring process (Sanchez-Monedero and Dencik 2019). For instance, some employers and labour market intermediaries use algorithmic recommendation systems to identify suitable candidates (Horton 2017). A widely-used example is LinkedIn's 'Recommended Candidates' feature, which automatically identifies potential matches to a job opening from its vast pool of profiles (Wiggers 2020). Employers also use AI technologies in applicant screening (Cowgill 2018) and some even in initial interviewing through automated chatbots (Sanchez-Monedero \& Dencik 2019).

A third related transformation is the use of digital data sources in skills validation and performance evaluation. Employers in the information technology industries have long used private professional certifications to validate candidates' skills in addition to, or instead of, degrees and other publicly regulated qualifications (Painter and Bamfield 2015). More recently, employers have begun to assess candidates' skills and suitability with automated computeradministered online tests (Hoffman, Kahn and Li, 2015; Sanchez-Monedero, Dencik and Edwards 2020). Some companies have also begun to use observational data from sources such as social media, voice analysis, emails, and customer feedback surveys to automatically produce quantitative measures of worker performance that are used in hiring, task assignment, and promotion decisions (Levy and Barocas 2018; Sanchez-Monedero \& Dencik 2019). We will refer to all these changes in employment and hiring practices associated with the adoption of digital technologies as digital labour market transformations.

\section{Digital disruptions and divides}

What implications do digital labour market transformations have for social mobility, and specifically, on the influence of parental class on occupational outcomes? On the one hand, 
digitalization could be disrupting the operation of the direct and indirect mechanisms that lead to class reproduction. The introduction of telework and remote hiring could mean that family social ties in the worker's local community are becoming less useful for obtaining and holding onto work. Moreover, the remote nature of the work and restricted social contact between employer and employee could reduce the influence of class cultural judgments, in sharp contrast with jobs requiring face-to-face interviews. The substitution of AI technologies for managerial judgment could likewise be drastically reducing the significance of social ties and cultural resources in hiring decisions. Moreover, the adoption of new digital forms of skill validation and performance measurement could be reducing the relative value of formal educational qualifications as signalling devices, eroding the influence of class origin induced inequalities in educational attainment. For these reasons, digital labour market transformations could be disrupting the influence of parental class background on occupational outcomes.

On the other hand, a recurring finding in the longstanding tradition of research on 'digital divides' is that people from privileged backgrounds tend to benefit from more from digital technologies (Scheerder, van Deursen and van Dijk 2017). Digital divides were first identified in the 1990s in access to the Internet. Older and poorer people and those living in rural areas were found to have less access than young, privileged city-dwellers (Riggins and Dewan 2005). As access became increasingly widespread in wealthier societies, research in the 2000s and 2010s turned towards inequalities in digital skills and the ways people use digital technologies. It was found that older and poorer internet users were less skilled and more likely to use digital technologies for entertainment than younger and richer users, who were more likely to exploit online educational and commercial opportunities (Scheerder, van Deursen and van Dijk 2017). More recently, research has begun to focus on a 'third-level' divide: differences between social groups in the extent to which outcomes from Internet and digital technology use are beneficial (Scheerder, van Deursen and van Dijk 2017). Echoing earlier research on divides in access, skills, and usage, researchers in the Netherlands have found that wealthier, more educated people are able to achieve better commercial, social and informational outcomes in digital media (van Deursen and Helsper 2015).

A newer stream of research on the use of data and algorithmic decision making in government and private organizations also suggests that these technologies can perpetuate and even accentuate inequalities (e.g., O’Neil, 2016; Eubanks, 2017). For instance, machine learning systems trained with biased data can continue to perpetuate the bias. Findings like these should cause us to treat with caution the idea that digital transformations might be reducing the influence of class in labour markets.

\section{An extreme case: Online platform labour}

Do digital labour market transformations disrupt class reproduction or not? In this study, we approach this question through an extreme case: the online market for remote freelance labour, in which self-employed workers sell labour remotely to clients through web-based platforms (Bergvall-Kåreborn \& Howcroft 2014; Kalleberg \& Dunn 2016; Wood et al. 2018). Virtually every kind of labour that can be delivered remotely over the Internet is transacted through these platforms, such as software development, graphic design, database management, customer service, sales lead generation, accounting, and legal work (Kässi \& Lehdonvirta 2018). The 
entire relationship from screening and matching to contracting, time tracking, billing, payment, and dispute resolution is mediated by the platform company.

Research suggests that such online platform work - also known as online freelancing, online gig work, and crowdwork - is a small but growing form of non-standard employment around the world, including in Europe. According to data from the European Commission Joint Research Centre's second COLLEEM survey, platform-mediated work is slowly rising over time and is now the main source of income for about $1.4 \%$ of adults across 16 EU member states (Pesole et al. 2018; Urzi Brancati et al. 2019). This figure includes both local gig economy platforms (taxi and delivery) as well as the web-based remote online labour platforms that are the focus of our study. Data collected directly from the largest online labour platforms suggests that the market grew approximately 50 percent from 2016 to 2019 (Kässi \& Lehdonvirta 2018). During the COVID-19 pandemic, the market has been volatile, with demand increasing for software development and technology specialists whose skills are needed as companies adjust to remote, digitally-mediated ways of working (Stephany et al. 2020). Leading platforms include Upwork, Freelancer, Fiverr, and PeoplePerHour.

This online labour market is an attractive setting for conducting a case study of technology, class, and occupations because digital transformations that are only nascent in the broader labour market are already fully operational in the online labour market. From start to finish, all interactions are remote and computer-mediated, with hiring interviews being conducted via video calls or instant messaging, or omitted in favour of purely document-based selection. Employers find suitable workers (and vice versa) from among the millions of possible matches by using the platforms' algorithmic search and recommendation engines (Horton 2017). Worker performance is tracked using digital data sources which are translated into metrics and scores that are displayed to employers (Lehdonvirta et al. 2019). For instance, Upwork displays a 'Job Success' score for each worker, which is calculated from previous client feedback and other inputs using an undisclosed algorithm. Employers can filter out candidates whose score falls below their chosen threshold or choose to include only candidates flagged as 'Top Rated' or 'Rising Star' by the platform's algorithms. Other platforms, such as PeoplePerHour, utilize automated computer-administered online tests to award badges that validate candidates' skills (Kässi \& Lehdonvirta 2019). Even clicks on a particular worker's profile are in some cases recorded and used as a proxy of employer interest in them (Horton 2017).

Due to its extremely digitalized nature, the online labour market thus represents a mostlikely case for theories of the attenuation of class reproduction, which posit that economic and technological progress reduce the influence of class origins on occupational attainment. If digital labour market transformations can disrupt the link between parental class and children's occupational outcomes, then we should be able to observe it here. Previous research has examined online workers' demographics (Pesole et al. 2018) and found that they are younger than the general population, but otherwise very diverse. No previous research has attempted to link measures of parental class into online labour market outcomes. We therefore seek to answer two main questions: (1) What are the class origins of online platform workers? and (2) Do online workers with more privileged class origins obtain better quality online work than those from less privileged class origins? 


\section{Data}

Data for the analyses comes from a 2019-2020 survey of freelancers working on three prominent online labour platforms in six European countries (Finland, Germany, Italy, Romania, Spain, UK) (N = 983). The survey was collected for the European Union's European Centre for the Development of Vocational Training (Cedefop 2020). Freelancers were selected using two methods. Two online platforms randomly sampled their registered workers and issued invitations and reminders to complete the survey $(\mathrm{N}=465)$. The remaining respondents $(\mathrm{N}=518)$ were identified by researchers using platform search functions. From each search results page, randomly selected workers were invited to to complete the survey, until quotas for country and sex were filled. Online platform freelancers are a hard-to-reach population whose exact demographic characteristics remain unknown, but the survey respondents are similar in age and educational characteristics to the large-scale randomized survey conducted for the European Union's COLLEEM project (Pesole et al. 2018).

Respondents' online occupations were grouped under the six categories developed for the Online Labour Index of the iLabour Project at the Oxford Internet Institute (Kässi and Lehdonvirta 2018): Clerical and Data Entry; Creative and Multimedia; Professional Services; Sales and Marketing Support; Software Development and Technology; Writing and Translation. Table 1 shows characteristic jobs for each category. To assess the class origins of platform workers, the survey asked respondents, "At the time you finished school, which category best matched your mother's/female guardian's main occupation?". The question was repeated for fathers/male guardians. Respondents chose from eight categories (with example occupations) based on the European Socio-Economic Classification (Harrison and Rose 2006): Higher Managerial/Professional, Lower Managerial/Professional, Middle-Class Service/Technical, Small Employer, Lower Technical, Lower Service, Unskilled, NonWorking.

In operationalizing the class origins of online workers, we follow the 'dominance' approach favoured in research on social mobility. The dominance approach takes the class of the parent/guardian with the more privileged class position as representative of the class origin of the respondent. This reflects the idea that the resources available to the family will be substantially influenced by the dominant parent. The dominance approach is considered superior to earlier approaches which took only male parents' class into account because of the rapid growth in female labour force participation in recent decades. Although recent scholarship has begun to draw the dominance approach into question and has suggested that averaging parental socioeconomic status is a superior approach (Thaning and Hällsten 2020), adopting an averaging approach to parental class background was not possible using the categorical data in the survey. Nevertheless, results of models below are robust to alternative specifications which include the non-dominant parental class as a separate independent variable as well as the interaction of the dominant and non-dominant, recommended by Thaning and Hällsten (2020). 
Table 1: Occupational Category and Characteristic Jobs

\begin{tabular}{|l|l|}
\hline $\begin{array}{l}\text { Occupational } \\
\text { Category }\end{array}$ & Characteristic Jobs \\
\hline $\begin{array}{l}\text { Clerical and Data } \\
\text { Entry }\end{array}$ & $\begin{array}{l}\text { Administrative Support, Data Entry, Market Research, } \\
\text { Presentations, Typing/Proofreading, Virtual Assistant }\end{array}$ \\
\hline $\begin{array}{l}\text { Creative and } \\
\text { Multimedia }\end{array}$ & $\begin{array}{l}\text { Animation, Audio Editing, Graphic Design, Photo Editing, Video } \\
\text { Editing }\end{array}$ \\
\hline Professional Services & $\begin{array}{l}\text { Accounting, Architecture, Business Services, Consulting, Data } \\
\text { Science \& Analytics, Engineering, Legal, Tax }\end{array}$ \\
\hline $\begin{array}{l}\text { Sales and Marketing } \\
\text { Support }\end{array}$ & $\begin{array}{l}\text { Customer Service, Digital Marketing, Sales \& Marketing, Social } \\
\text { Media }\end{array}$ \\
\hline $\begin{array}{l}\text { Software } \\
\text { Development and } \\
\text { Technology }\end{array}$ & $\begin{array}{l}\text { IT and Networking, Mobile Software Development, } \\
\text { Programming, Software Development, Web Development }\end{array}$ \\
\hline $\begin{array}{l}\text { Writing and } \\
\text { Translation }\end{array}$ & Translation, Writing \\
\hline
\end{tabular}

\section{Analyses}

What are the class origins of online platform workers?

Figure 1 reveals that online platform workers tend to have privileged class origins; a pattern repeated across all countries in the sample in Figure 2. These proportions are far in excess of recent estimates of the size of the Higher Managerial/Professional, Lower Managerial/Professional and Middle-Class Service/Technical classes in national populations (Rose and Harrison 2010). Evidence from Figures 1 and 2 therefore reveals a digital divide in access to online platform work, which is consistent with expectations from theories of the persistence of class reproduction. It should be noted, however, that $28 \%$ of platform workers nevertheless come from less privileged backgrounds, that is, classes other than Higher Managerial/Professional, Lower Managerial/Professional or Middle-Class Service/Technical. 
Figure 1: Dominant Parental Class Background

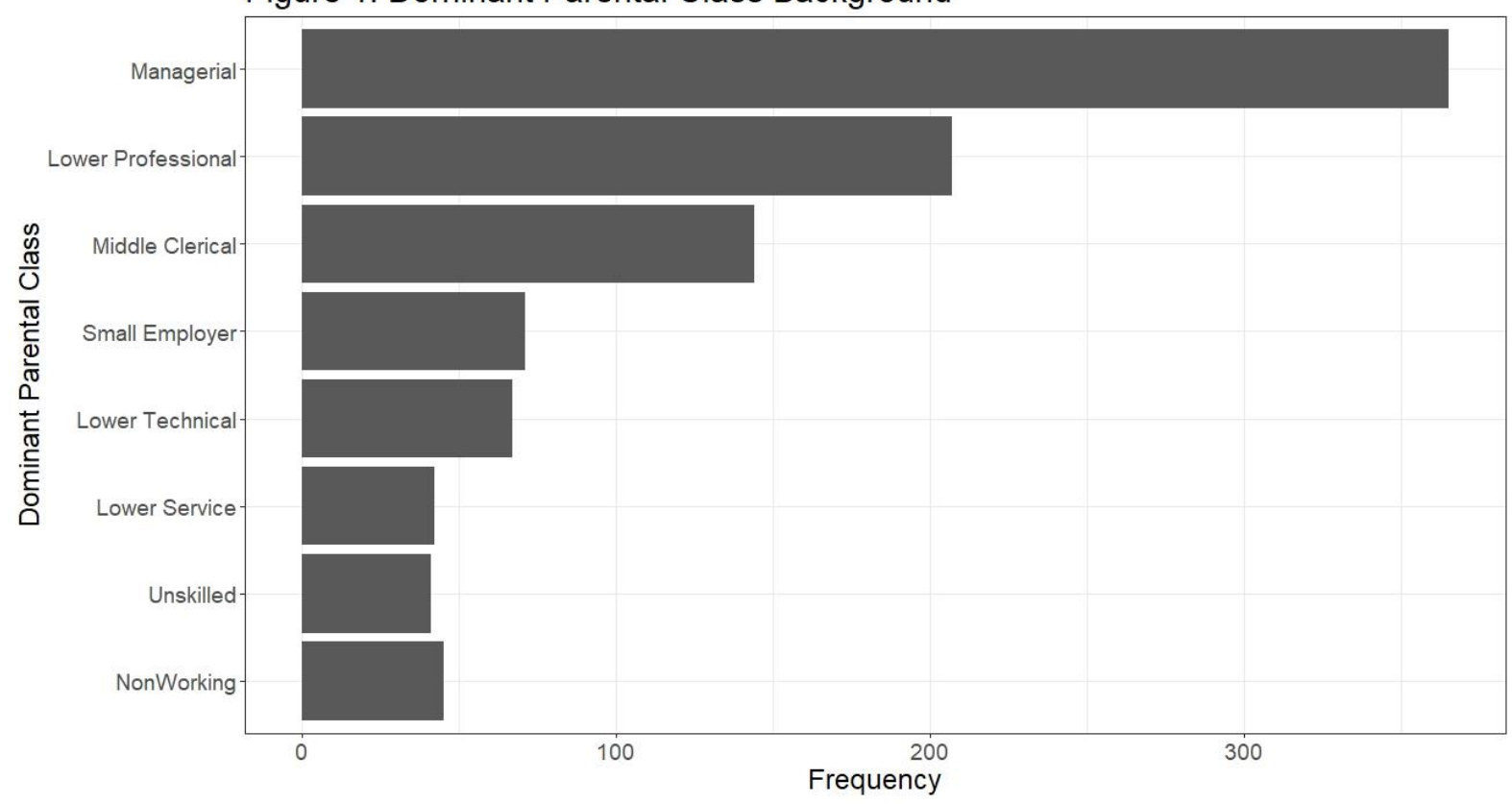

Figure 2: Dominant Parental Class Background by Country

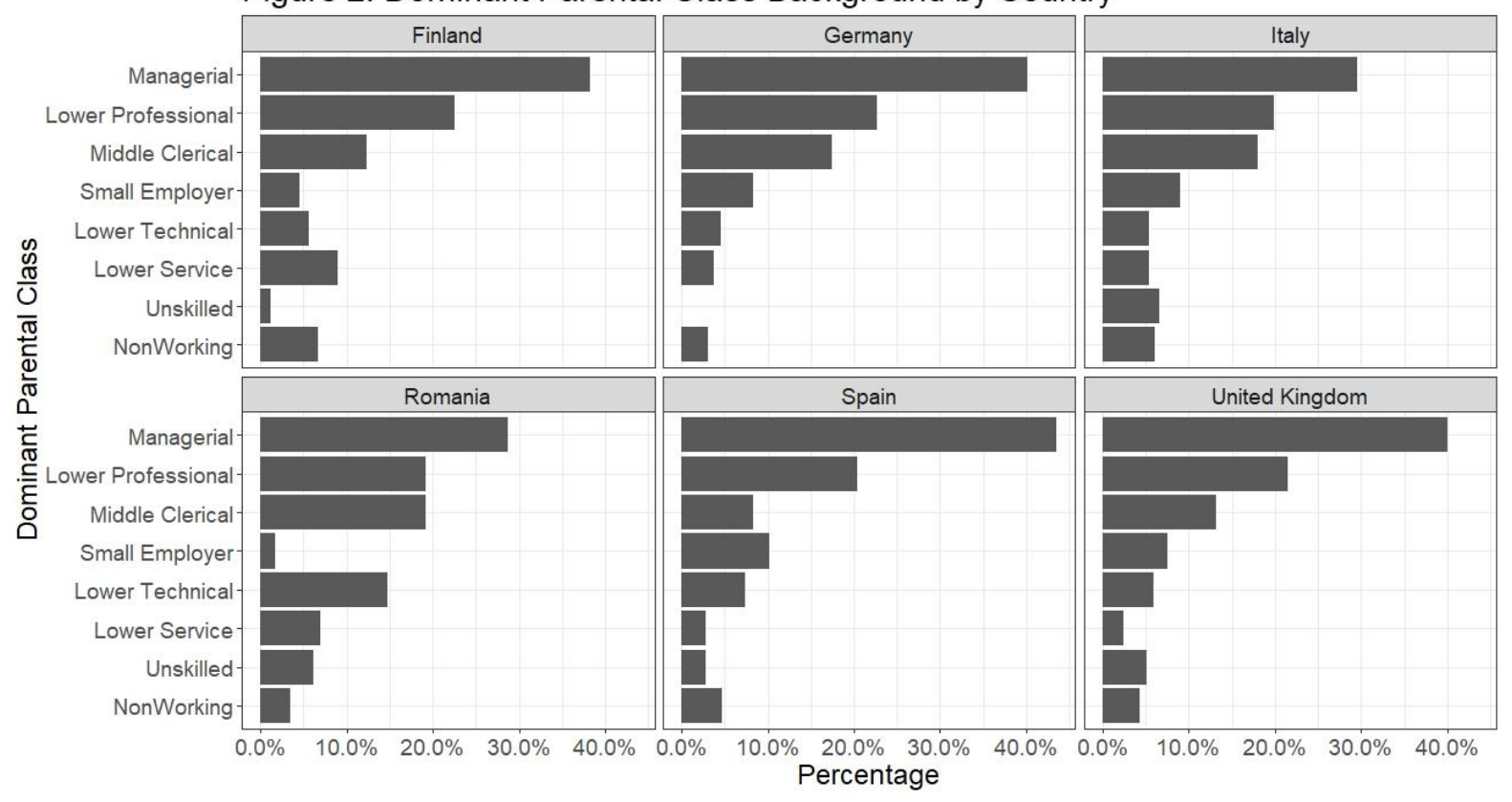

Does class origin affect the quality of occupation acquired by online workers?

To assess whether workers with more privileged class origins obtain higher quality online work, we investigated patterns of class origin in the distribution of occupational categories, pay, and job security. As the dependent variable in the analysis of occupational groups is comprised of the six unordered iLabour occupational categories, we estimated a multinomial logistic regression (1). The multinomial logistic regression enables us to estimate the relative risk of a respondent acquiring work in five of the occupational categories against a single comparator category. As the analysis seeks to assess whether workers with more privileged 
backgrounds acquire higher quality work, the category with the lowest quality work, 'Clerical and Data Entry', acts as the comparator. Workers in this category receive both the lowest pay (Figure 3) and use the fewest skills (as calculated by taking the mean for each occupational category of the sum of ten binary variables measuring the use of different skills; Table 2). The model is estimated five times, once for each occupational category $i$. Each of the independent variables is therefore associated with five coefficients, which indicate how a one unit increase in the independent variable is associated with a change in the logged risk ratio (the natural log of the probability of occupation $i$ divided by the probability of Clerical and Data Entry) of a respondent being in occupational category $i$ instead of Clerical and Data Entry. Substantive interpretations are provided with results below.

$\ln \left(\frac{P(\text { iLabour }=i)}{P(\text { iLabour }=\text { Clerical })}\right)=\beta_{i 0}+\beta_{i 1}$ Salariat $+\beta_{i 2}$ Education $+\sum_{j=3}^{n} \beta_{i j} X_{i j}+\varepsilon$

$i \in\{$ Creative and Multimedia; Professional Services; Sales and Marketing Support; Software Development and Technology; Writing and Translation $\}$

Figure 3: Hourly Rate of Online Platform Workers by Occupational Category

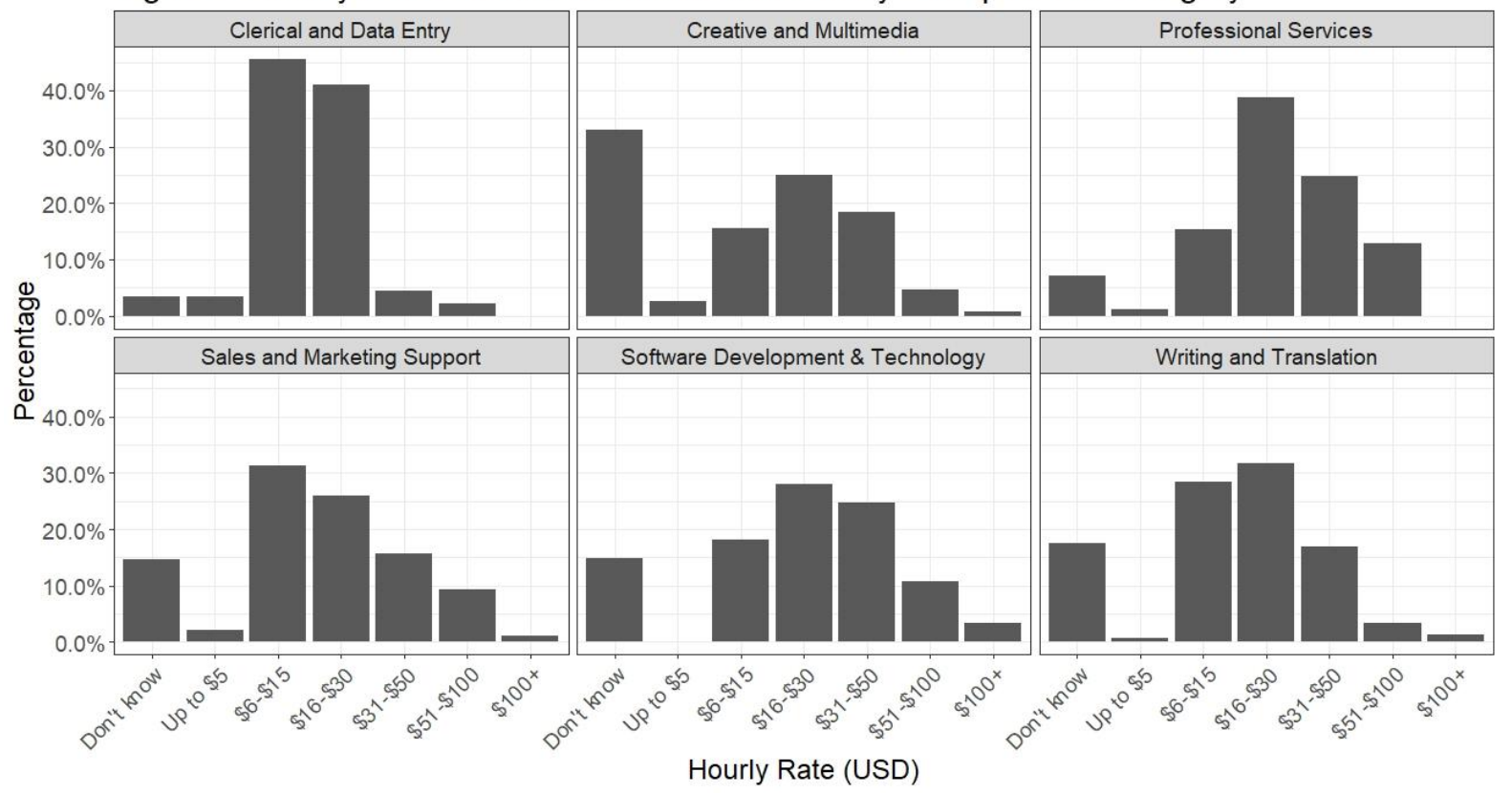


Table 2: Skill Use by Occupational Category

\begin{tabular}{|l|l|}
\hline Occupational Category & Mean Skill Use [max. 10] \\
\hline Clerical and Data Entry & 4.50 \\
\hline Creative and Multimedia & 4.55 \\
\hline Professional Services & 5.11 \\
\hline Sales and Marketing Support & 4.71 \\
\hline $\begin{array}{l}\text { Software Development \& } \\
\text { Technology }\end{array}$ & 5.05 \\
\hline Writing and Translation & 4.71 \\
\hline
\end{tabular}

Salariat is a dummy variable for whether the occupation of a respondent's dominant parent was categorized as Higher Managerial/Professional, Lower Managerial/Professional or Middle-Class Service/Technical. (The categorization of small employers is a known difficulty in class analysis. They account for just 71 observations in the sample. Results presented below are robust to the inclusion of small employers with the salariat or their exclusion from the analysis.) Workers in salariat occupations typically experience a range of benefits not afforded to those outside of the salariat: higher wages, wages that peak later in life, more secure contracts, occupational pensions, etc. (Goldthorpe and MacKnight 2006). Therefore, they constitute more privileged class origins. A binary operationalization of class origin therefore captures a significant cleavage in the class structure while facilitating interpretation of the results. Table 3 shows descriptive statistics for the percentage of salariat and non-salariat class origin workers in different occupational categories.

Table 3: Parental Class Origin by Occupational Category

\begin{tabular}{|l|r|r|r|}
\hline Occupational Category & $\begin{array}{l}\text { Salariat } \\
\text { Origin } \\
\text { Workers (\%) }\end{array}$ & $\begin{array}{l}\text { Non-Salariat } \\
\text { Origin } \\
\text { Workers (\%) }\end{array}$ & $\begin{array}{l}\text { Difference: } \\
\text { Salariat - } \\
\text { Non-Salariat }\end{array}$ \\
\hline Clerical and Data Entry & 8.2 & 11.8 & -3.6 \\
\hline Creative and Multimedia & 28.2 & 28.7 & -0.5 \\
\hline Professional Services & 9.5 & 6.8 & +2.9 \\
\hline Sales and Marketing Support & 11.1 & 6.8 & +4.3 \\
\hline $\begin{array}{l}\text { Software Development \& } \\
\text { Technology }\end{array}$ & 12.1 & 13.3 & -1.7 \\
\hline Writing and Translation & & 32.6 & 100 \\
\hline
\end{tabular}

In a first stage, the association between Salariat and Occupation was estimated in bivariate models. Results in Figure 4 reveal that, without controls, associations between class 
origins and online occupation are significant for only two occupational classes (full results in the Appendix). Having a parent from the Salariat is not significantly associated with a greater or lesser chance of working in Creative and Multimedia, Software Development and Technology, or Writing and Translation relative to Clerical and Data Entry. Class origins are therefore largely unrelated to occupational outcomes on online platforms.

However, having a Salariat parent does increase the chance of working in Professional Services and Sales and Marketing Support relative to Clerical and Data Entry. The substantive magnitudes of the two significant associations are considerable. The horizontal axis in Figure 4 measures the exponentiated coefficients for Salariat in models for each occupational category. Exponentiating undoes the effect of the natural $\log$ operator, $\ln ()$, on the left-hand side of equation (1). The value of the horizontal axis is therefore equivalent to the probability of being in occupational category $i$ divided by the probability of being in Clerical and Data Entry, also known as relative risk. One interpretation of a relative risk of 2, as in the case of Professional Services, is that having a Salariat parent doubles the probability of being in Professional Services (the numerator), while keeping the probability of Clerical and Data Entry (the denominator) equal for Salariat and non-Salariat origin workers. A converse interpretation is that the probability of Clerical and Data Entry is halved, keeping the probability of Professional Services constant. The correct interpretation is likely a mixture of both: Salariat origin workers have a lower probability of being in Clerical and Data Entry and a higher probability of being in Professional Services, as seen in Table 3. The estimated association was of a similar magnitude for Sales and Marketing work.

Figure 4. Association between salariat background and online occupation

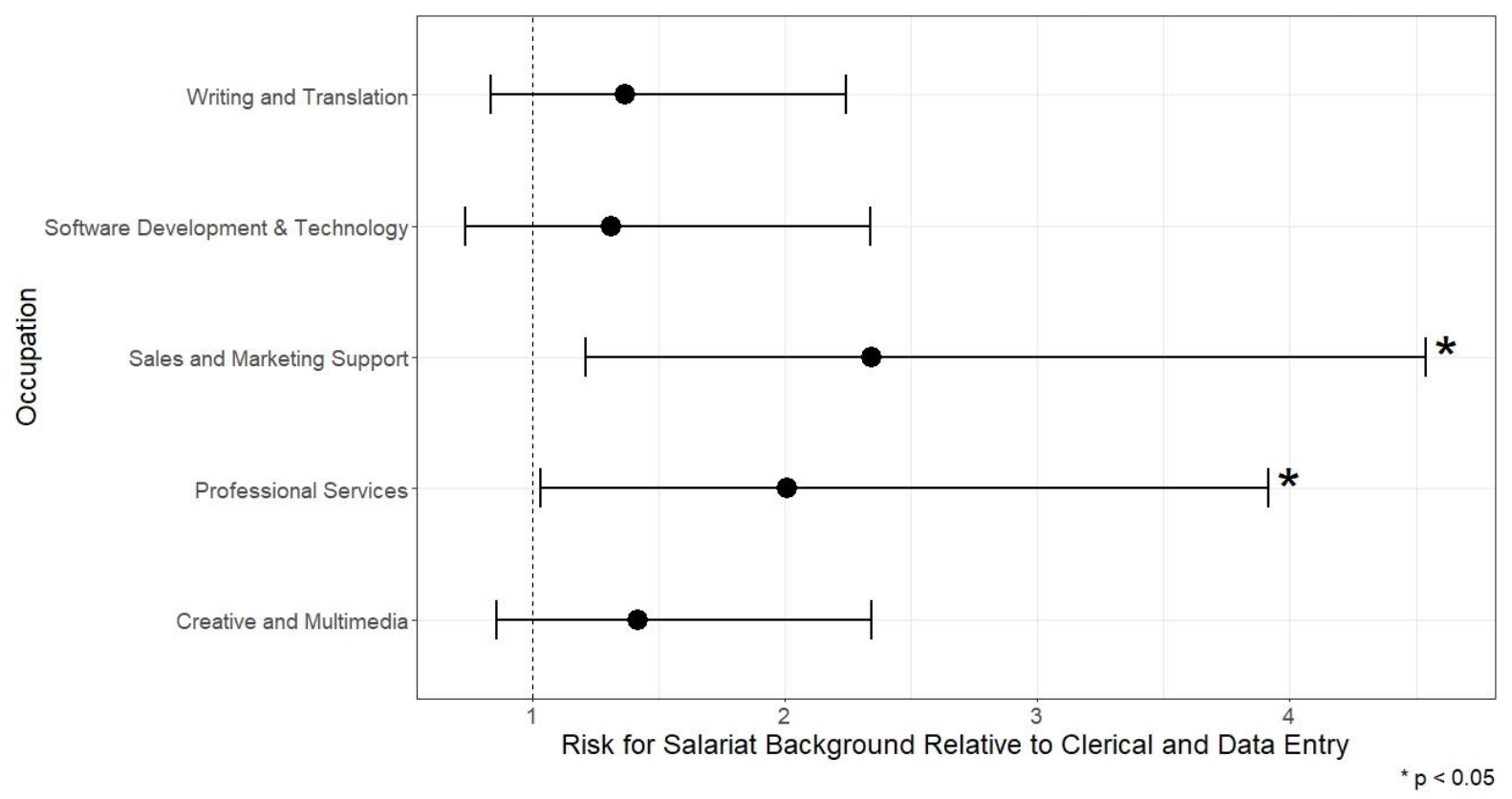

The two significant bivariate associations may be the result of class origin induced differences in educational attainment. To examine this possibility, educational attainment is operationalized as a dummy variable for whether workers have attained at least an undergraduate degree. Figure 5 plots the results of models for Professional Services and Sales and Marketing Support which first introduces an education control and then a fuller suite of 
controls. When education is included, the association for Sales and Marketing Support remains significant. However, the association between Salariat origins and Professional Services is no longer significant. This reveals that the influence of class origins for this category is mediated by class differentials in education attainment. This is unsurprising for Professional Services work, which mainly includes occupations that require specific educational qualifications, such as accountancy and legal advice (Table 2). These results are robust to an alternative, but less parsimonious, specification in which educational attainment is operationalized by separate dummy variables for the nine categories of educational attainment recorded in the survey, from no formal schooling to doctorate.

In a final stage, control variables, $X_{i k}$, were introduced for other relationships which may help to explain associations between class origin and occupation: age, sex, country, platform, and number of jobs completed on the platform. The significant association for Sales and Marketing Support remains even with this full suite of controls. Salariat class origins are therefore directly related to working in Sales and Marketing Support relative to Clerical and Data Entry, assuming that relevant variables have been included in the model.

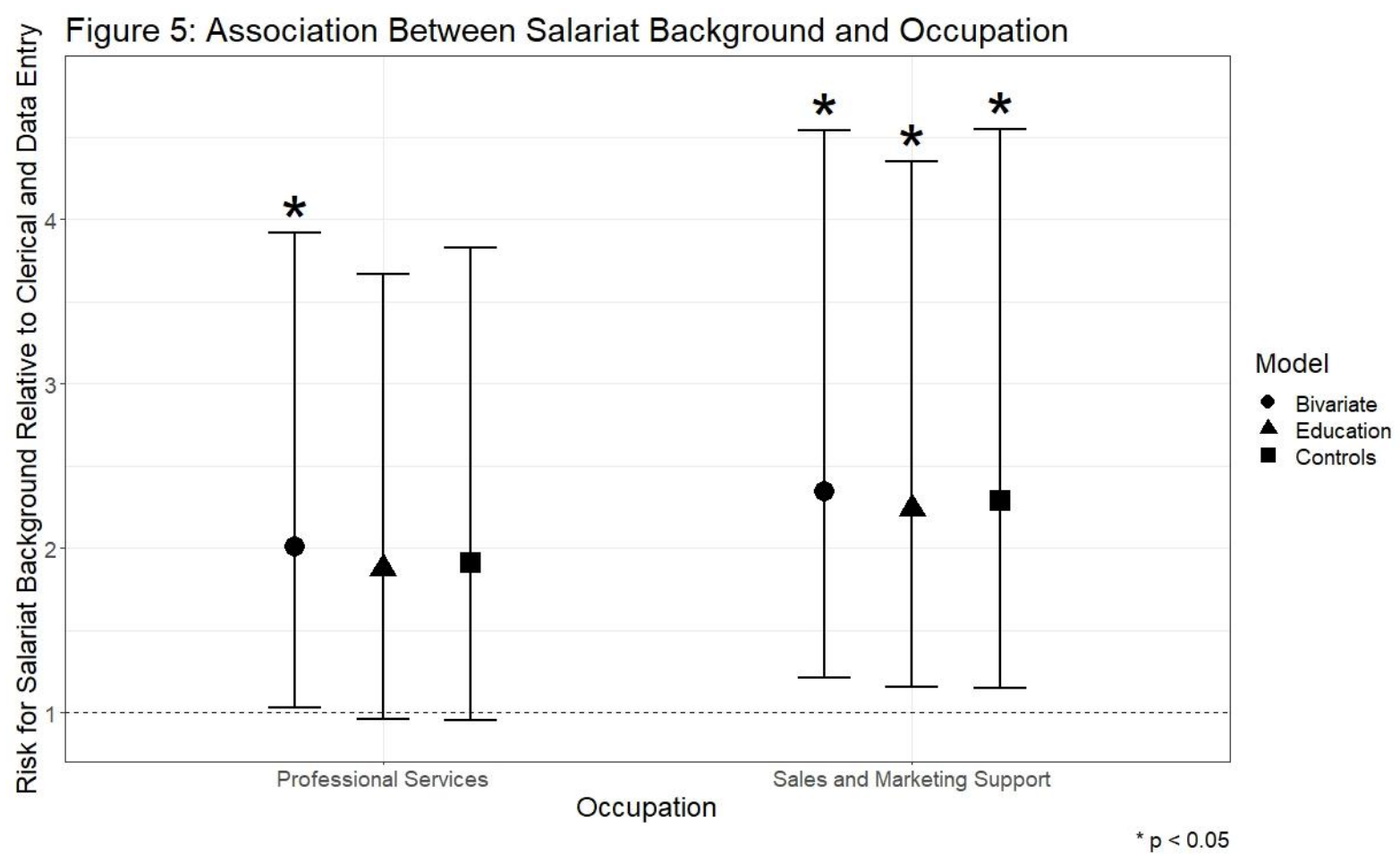

To assess whether workers with Salariat backgrounds obtain better quality work on online platforms, we also estimated models for dependent variables that measure pay and job security. In relation to pay, respondents were asked about their hourly rates (six categories, ' $\$ 5$ or below' to 'more than \$100') and whether they thought their pay was too low (five categories, 'Strongly Agree' to 'Strongly Disagree'). For job security, respondents were asked whether they felt replaceable and whether they felt they could easily replace their clients (five categories, 'Strongly Agree' to 'Strongly Disagree'). As these dependent variables are ordered categories, ordinal logistic regressions were estimated using the same independent variables as 
in the models for occupational groups above. Full results can be found in the Appendix. Results revealed no association for Salariat class background with pay variables or for feeling able to easily replace clients. However, Salariat origins were significantly associated with workers being less likely to agree that they felt replaceable $(\beta=-0.444, p=0.012)$. Substantively, the odds of a worker with a Salariat parent agreeing rather than being neutral to the question of whether they feel replaceable are about two thirds of those of a worker without a Salariat parent. As with occupational categories above, there is therefore only slight evidence to suggest that worker class origins influence the quality of their work on online labour platforms.

\section{Discussion}

Results have revealed, for the first time, that class origins are strongly associated with the use of online platforms for work. Those engaging in remote online platform work are overwhelmingly from privileged class backgrounds: $72 \%$ of sampled workers reported having at least one parent in the three most privileged of the eight classes of the European socioeconomic classification. This finding is the first empirical evidence of a divide in the use of platforms for remote work and is consistent with previous research on digital divides which has found that the more privileged are more likely to use digital technologies for commercial opportunities. In addition, this finding is consistent with theories of the persistence of the influence of class origins on occupational attainment rather than theories predicting the attenuation of this relationship. If, as per attenuation theories, technological and economic development are weakening the relationship between class origins and occupational attainment, then we would not have expected to observe such a strong link between parental class and the online platform economy, which is at the forefront of technological and economic change.

That workers from privileged class backgrounds are so attracted to platform work may be surprising, given widely held beliefs about how social isolation and fragmentary working patterns in precarious occupations are undermining labour standards (Standing 2011). The predominance of workers with privileged backgrounds implies that pay and conditions in online platform work are sufficiently attractive for those who are likely to have good alternative employment options. Contrary to more pessimistic assessments of the gig economy, findings here therefore contribute evidence towards the claim that the gig economy can provide 'good' work to some. Such a claim is also supported by previous research which finds that online returns in some occupations can outstrip those in the conventional labour market (Sundarajan 2016; Pesole et al. 2018; Lehdonvirta et al., 2019). In addition, work values surveys have revealed that contemporary workers are drawn to the kinds of autonomous and flexible forms of employment that characterize online gig work (Taylor et al. 2017). Indeed, these factors are the two most common reported motivations of workers in the survey studied here: being their 'own boss' motivated $48 \%$ of the sample to work on the platform; $48 \%$ were motivated by 'schedule control'.

Despite the predominance of those with privileged class origins, $28 \%$ of workers nevertheless came from less privileged backgrounds. This raised the possibility that the more privileged could also be holding online occupations with better working conditions than the online occupations held by less privileged. However, a second set of analyses revealed, for the first time, that class origins had little influence on the distributions of types of work, pay, or 
job security among those doing remote platform work. Class origins were not significantly associated with pay levels and were only weakly associated with one measure of job security. Moreover, workers with more privileged class backgrounds were not generally associated with higher quality online occupations. There were no significant differences in the class backgrounds of those engaged in Creative and Multimedia, Software Development and Technology or Writing and Translation relative to Clerical and Data Entry work. In contrast with the conclusions of the first analysis, this absence of stratification by class of origin in the quality of platform occupation is more consistent with theories predicting the attenuation of the influence of class origins on occupational attainment than with theories predicting its persistence.

There were, nevertheless, exceptions to this finding. Workers with more privileged backgrounds were more likely to engage in Professional Services and Sales and Marketing work, relative to the lower quality Clerical and Data Entry work. However, the significance of the association for Professional Services disappeared with the inclusion of a control for education. This implies that differences in education levels due to class of origin remain important in accessing this category of work. Even if the digitalized labour market itself is class agnostic, stratification into different educational streams takes place before labour market entry, which then influences labour market outcomes especially in occupations that require specific qualifications, such as legal advice and architecture.

Sales and Marketing remained significantly associated with privileged class origins even with a full suite of controls. This implies that despite the use of digital technologies to screen and select candidates, privileged class origins still provide workers with resources that attract employers in this category. Considering the forms of interpersonal skills required for sales work, these may be the kinds of embodied cultural resources that are reassuring and persuasive to customers: genteel forms of self-presentation communicating high social status. Exactly how these resources are signalled by candidates to employers in a highly digitalized labour market remains unclear. Are algorithmic rankings and recommendations sensitive to names, profile photos, written communication styles, and accents that suggest privilege, or is the outcome fully explained by the remaining human element in the hiring process? Given that only Sales and Marketing work was associated with privileged class origins after controls were applied, the human element seems a more likely explanation.

Why are the two sets of analyses consistent with contrasting theoretical approaches? Why are class origins important in explaining who uses online platforms for work but far less so for the kinds of work they do on the platforms? We argue that this apparent contradiction is the result of the operation of worker supply and client demand: (i) workers differentially select into (or away from) online platform work because of class origin but (ii) clients select platform workers based on characteristics that in most cases are unrelated to class origin. Considering the first half of this explanation, workers with less privileged class origins may be less likely to select into platform work because of both the risks and the set-up costs involved. Hardware, software, and reliable Internet access are expensive. Building an online reputation takes time and may involve initial periods of low pay. Moreover, pay is likely to be much more volatile than in conventional forms of work, as each online job, or 'gig', is negotiated separately. As many platform workers are young ( $40 \%$ of the sample were thirty years of age or younger), parental support is more likely to help those with more privileged origins to absorb these costs and risks (Goldthorpe 2007). Moreover, workers in countries where English is not the native 
language face the additional set up cost of acquiring proficiency in English, the dominant language in the online labour market (Kässi and Lehdonvirta 2018). English proficiency is likely related to the ability of parents to invest in their children's education and is therefore another factor weighing against platform access for those with less privileged class backgrounds (Azzolini et al. 2020).

Nevertheless, it could also be argued that workers with privileged class origins predominate because of greater competitivity. Workers with more privileged backgrounds tend to have superior educational qualifications to those with less privileged backgrounds (Goldthorpe 2007). This may help privileged workers to outcompete their less privileged rivals, encouraging them to exit the platform at a faster rate. However, a mechanism linking privileged class backgrounds to superior competitivity should also lead to workers from more privileged backgrounds securing higher quality work than the less privileged. Evidence from the second set of analyses largely contradicts this expectation. This implies that differential selection into platform work is better able to account for the predominance of workers from more privileged class backgrounds than differential competitivity.

How then does client demand result in very little stratification by class origin in the quality of online occupation among those who do work on platforms? We argue that clients are selecting workers on characteristics unrelated to class origin. Instead, clients avail themselves of extensive worker job histories, reputation ratings, and observational performance metrics provided by platforms. Platform algorithms also use such data to suggest workers that match clients' demands. Indeed, results revealed that the number of successfully completed projects (the only measure of skill or performance available consistently across the sampled platforms) was significantly associated with the quality of work carried out by the sampled workers (full results in the Appendix). This interpretation is also consistent with a wealth of research showing that various platform metrics explain significant amounts of variation in pay and employment in the online labour market (eg., Pallais 2014, Lin et al. 2016, Lehdonvirta et al. 2019). Moreover, digitally mediated communication likely reduces the impact of class-cultural discrimination. To assess these claims, future research should seek to investigate in greater depth the factors that influence client hiring decisions, an area of the platform economy that remains understudied (a good exception is Horton 2017). Overall, our findings suggest that while technological transformations of labour markets may reproduce digital divides in access to work, digital transformations may succeed in eroding class-based differences in the selection of workers by employers.

\section{Conclusions}

Labour markets today are undergoing significant transformations associated with the adoption of new digital technologies. Candidates are screened using data and algorithmic decision making. Skills are validated with online tests and customer feedback ratings. Workplace communications take place over digital media. There are good reasons to speculate that such digital transformations could be disrupting the well-established link between parental class and children's occupational attainment. Online labour platforms offer an extreme case of labour market digitalization in which we should see the effects of such transformations most clearly today. 
We found that online platform workers - those who have succeeded in establishing themselves in the online freelancing market - are disproportionately from privileged class backgrounds. This is the first demonstration of a digital divide in the use of online platforms for work. The unequal distribution of parental resources permits or prevents access to the new world of digitally-mediated work. Parental resources also shape access to some occupations in the online labour market. However, class background had surprisingly little influence on job quality, which varied significantly even within occupations. Job quality is instead shaped by individual digital metrics such as feedback ratings. Clients on platforms select, reward, and sanction workers using digital affordances largely disconnected from the worker's class origin.

A possible interpretation of these findings is that labour market digitalization is to some extent perpetuating class reproduction in terms of occupational selection, while at the same time decoupling occupation classes from job quality. That is, privileged workers still have an easier time getting into exclusive labour markets and occupations, but such occupational attainment no longer guarantees job quality as before, reducing the economic significance of the privilege. This does not have to imply that digitalized labour markets are more egalitarian; indeed, earnings on online labour platforms are highly unequally distributed. But the inequality and stratification evident in these markets is not simply a reproduction of old class hierarchies.

\section{References}

Autor, David H. and David Dorn. 2013. "The Growth of Low-Skill Service Jobs and the Polarization of the US Labor Market". American Economic Review 103(5):1553-1597. https://doi.org/10.1257/aer.103.5.1553

Azzolini, Davide, Sabrina Campregher and Joan E Madia. 2020. "Formal instruction vs informal exposure. What matters more for teenagers' acquisition of English as a second language?" Research Papers in Education. https://doi.org/10.1080/02671522.2020.1789718

Bell, Daniel. 1973. The Coming of Post-Industrial Society: A Venture in Social Forecasting. New York: Basic Books.

Bergvall-Kåreborn, Birgitta and Debra Howcroft. 2014. "Amazon Mechanical Turk and the commodification of labour". New Technology Work and Employment 29(3):213-223. https://doi.org/10.1111/ntwe.12038

Blau, Peter M. and Otis D. Duncan. 1967. The American Occupational Structure. Chicago: Chicago University Press.

Braverman, Harry. 1974. Labor and Monopoly Capitalism: The Degradation of Work in the Twentieth Century. New York: Monthly Review Press.

Bresnahan, Timothy F. 1999. "Computerisation and Wage Dispersion: An Analytical Reinterpretation". The Economic Journal 109(456):390-415. https://doi.org/10.1111/1468$\underline{0297.00442}$

Cowgill, Bo. 2017. "Bias and Productivity in Humans and Algorithms: Theory and Evidence from Résumé Screening”. (working paper, Columbia University, New York, NY, 2018) 
Di Pietro, Giorgio. 2002. "Technological change, labor markets, and 'low-skilled, lowtechnology traps'. Technological Forecasting and Social Change 69(9):885-895. https://doi.org/10.1016/S0040-1625(01)00182-2

Dunn, Michael. 2017. "Digital Work: New Opportunities or Lost Wages?" American Journal of Management 17:10-27. https://doi.org/10.5465/ambpp.2016.11689abstract

Eubanks, V. (2017). Automating inequality: How high-tech tools profile, police, and punish the poor (First Edition). St. Martin's Press.

Frey, Carl Benedikt and Michael A. Osbourne. 2017. "The future of employment: How susceptible are jobs to computerisation?". Technological Forecasting and Social Change 114:254-280. https://doi.org/10.1016/j.techfore.2016.08.019

Friedman, Sam and Danial Laurison. 2019. The Class Ceiling: Why it Pays to be Privileged.

Goldin, Claudia and Lawrence F. Katz. 1998. "The Origins of Technology-Skill Complementarity". The Quarterly Journal of Economics 113(3):693-732. https://doi.org/10.1162/003355398555720

Goldthorpe, John, H. 2007. On Sociology Vol. II. Stanford: Standford University Press.

Goldthorpe, John, H. and Abigail MacKnight. 2006. "The Economic Basis of Social Class". In Mobility and Inequality: Frontiers of Research in from Sociology and Economics, edited by Morgan, S., Grusky, D. B., Fields, D. S., pp.109-136. Stanford: Stanford University Press.

Goos, Maarten and Alan Manning. 2007. "Lousy and Lovely Jobs: The Rising Polarization of Work in Britain". Review of Economics and Statistics 89(1):118-133. https://doi.org/10.1162/rest.89.1.118

Goos, Maarten, Alan Manning and Anna Salomons. 2009. "Job Polarization in Europe". American Economic Review 99(2):58-63. https://doi.org/10.1257/aer.99.2.58

Granovetter, Mark S. 1995. Getting a job: a study of contacts and careers. Chicago: University of Chicago Press.

Harrison, Eric and David Rose. 2006. The European socio-economic classification (ESec) user guide. Colchester: Institute for Social and Economic Research, University of Essex. https://www.iser.essex.ac.uk/files/esec/guide/docs/UserGuide.pdf

Horton, John J. 2017. "The effects of algorithmic labor market recommendations: evidence from a field experiment". Journal of Labor Economics 35(2). https://doi.org/10.1086/689213

Huws, Ursula, Wener B. Korte and Simon Robinson. 1990. Telework: Towards the Elusive Office. Chichester: John Wiley \& Sons.

Kalleberg, Arne L. and Michael. 2016. "Good Jobs, Bad Jobs in the Gig Economy." Perspective on Work 20(2):10-14.

Kässi, Otto and Vili Lehdonvirta. 2018. "Online Labour Index: Measuring the Online Gig Economy for Policy and Research”. Technological Forecasting and Social Change 137:241248 
Kässi, Otto and Vili Lehdonvirta. 2019. "Do Digital Skills Certificates Help New Workers Enter the Market? Evidence from an Online Labour Platform". CESifo Working Paper No. 7810 .

Levy, Karen, and Solon Barocas. 2018. "Refractive Surveillance: Monitoring Customers to Man- age Workers". International Journal of Communication 12 (2018):1166-1188.

Mokhtarian, Patricia L. 1991. "Telecommuting and travel: state of the practice, state of the art". Transportation 18:319-342. https://doi.org/10.1007/BF00186563

O’Neil, C. (2016). Weapons of math destruction: How big data increases inequality and threatens democracy (First edition). Crown.

Painter, Anthony and Louise Bamfield. 2015. The new digital learning age: how we can enable social mobility through technology. London: The Royal Society of Arts.

Pesole, Annarosa, Cesira Urzi Brancati, Enrique Fernández Macías, Federico Biagi and Ignacio González Vázquez. 2018. Platform Workers in Europe. JRC Science for Policy Report, Brussels: European Commission.

Riggins, Frederick J. and Sanjeev Dewan. 2005. "The digital divide: current and future research directions". Journal of the Association for Information Systems 6(12):13

Rose, David and Eric Harrison (eds). 2010. Social Class in Europe: An Introduction to The European Socio-economic Classification. London: Routledge.

Rumberger, Russell W. and Henry M. Levin. 1985. "Forecasting the impact of new technologies on the future job market." Technological Forecasting and Social Change 27(4):399-417. https://doi.org/10.1016/0040-1625(85)90020-4

Sanchez-Monedero, Javier., Lina Dencik and Lilian Edwards. 2020. "What does it mean to 'solve' the problem of discrimination in hiring? Social, technical and legal perspectives from the UK on automated hiring systems.”. Presented at: ACM Conference on Fairness, Accountability, and Transparency (ACM FAT), Barcelona, Catalonia, 27-30 January 2020.

Sanchez-Monedero, Javier and Lina Dencik. 2019. "The datafication of the workplace." Working paper. Cardiff: datajusticeproject.net. Available at: https://datajusticeproject.net/wpcontent/uploads/sites/30/2019/05/Report-The-datafication-of-the-workplace.pdf

Scheerder, Anique, Alexander van Deursen and Jan van Dijk. 2017. "Determinants of Internet skills, use and outcomes: A systematic review of the second- and third-level digital divide". Telematics and Informatics 34(8):1607-1624. https://doi.org/10.1016/j.tele.2017.07.007

Standing, Guy. 2011. The Precariat: The New Dangerous Class. London: Bloomsbury Academic.

Stephany, Fabian, Michael Dunn, Steve Sawyer and Vili Lehdonvirta. 2020. "Distancing Bonus or Downscaling Loss? The Changing Livelihood of US Online Workers in Times of COVID-19". Journal of Economic and Social Geography 111(3):561-573. https://doi.org/10.1111/tesg.12455

Sundarajan, Arun. 2016. The Sharing Economy: The End of Employment and the Rise of Crowd-Based Capitalism. Cambridge, Massachusetts: MIT Press. 
Taylor, Matthew, Greg Marsh, Diane Nicol and Paul Broadbent. 2017. Good Work: The Taylor Review of Modern Working Practices. Available at: https://www.gov.uk/government/publications/good-workthe-taylor-review-of-modernworking-practices

Thaning, Max and Martin Hällster. 2020. "The End of Dominance? Evaluating Measures of Socio-Economic Backgrounds in Stratification Research". European Sociological Review 36(4):533-547. https://doi.org/10.1093/esr/jcaa009

Treiman, Donald J. 1970. "Industrialization and Social Stratification". In Social Stratification: Research and Theory for the 1970s, edited by E. O. Laumann, pp.207-234, Indianapolis: Bobbs Merrill.

Unger, Roberto M. 2019. The Knowledge Economy. London: Verso.

Urzi Brancati, Cesira, Annarosa Pesole and Enrique Fernández Macías. 2019. Digital Labour Platforms in Europe: Numbers, Profiles, and Employment Status of Platform Workers. JRC Science for Policy Report, Brussels: European Commission.

van Deursen, Alexander and Ellen J. Helsper. 2015. "The Third Level Digital Divide: Who Benefits the Most from Being Online?". Communication and Information Technologies Annual (Studies in Media and Communications 10:29-52. https://doi.org/10.1108/S2050$\underline{206020150000010002}$

Wiggers, Kyle L. 2020. "Linkedin details AI tool that better matches jobs to candidates". https://venturebeat.com/2020/07/30/linkedin-details-ai-tool-that-better-matches-jobs-tocandidates/

Wood, Alex .J., Vili Lehdonvirta and Mark Graham. 2018. "Workers of the Internet unite? Online freelancer organisation in six Asian and African countries". New Technology, Work and Employment 33(2):95-112. 